\title{
On the Development of a Zinc Vapor Condensation Process for the Solar Carbothermal Reduction of Zinc Oxide
}

\author{
N. TZOUGANATOS,${ }^{1}$ M. DELL'AMICO,${ }^{2}$ C. WIECKERT,${ }^{1}$ J. HINKLEY,${ }^{2}$ \\ and A. STEINFELD ${ }^{3,4}$
}

\begin{abstract}
1.-Solar Technology Laboratory, Paul Scherrer Institute, 5232 Villigen, Switzerland. 2.-CSIRO Energy Centre, Mayfield West, Newcastle, NSW 2304, Australia. 3.-Department of Mechanical and Process Engineering, ETH Zurich, 8092 Zurich, Switzerland. 4.-e-mail: aldo.steinfeld@
\end{abstract} ethz.ch

In the conventional Imperial Smelting Process, the dominating pyrometallurgical zinc production process, zinc vapor is recovered from the furnace offgas by absorption into an intense spray of molten lead droplets in a splash condenser, followed by separation of zinc from the $\mathrm{Zn}-\mathrm{Pb}$ alloy upon cooling from $550^{\circ} \mathrm{C}$ to $450^{\circ} \mathrm{C}$ by taking advantage of the decrease in the solubility of zinc in lead at lower temperatures. The adaptation of this condenser technology into a solar-driven thermochemical plant using concentrated solar energy faces several drawbacks owing to its mechanical complications and the continuous recirculation of large quantities of lead. An alternative zinc condenser concept involving gas bubbling through a zinc liquid bath of the off-gas evolved from the carbothermal reduction of $\mathrm{ZnO}$ is thus proposed and numerically modeled for transient heat and mass transfer. Condensation of bubbles containing $53.5 \%$ of noncondensable gases yielded chemical conversions of $\mathrm{Zn}(\mathrm{g})$ to $\mathrm{Zn}(\mathrm{l})$ in the range of $95.6-99.8 \%$ for operation in the temperature range $500-650^{\circ} \mathrm{C}$ while conversions of $\mathrm{Zn}(\mathrm{g})$ to $\mathrm{ZnO}$ in the order of $10^{-6}$ were obtained, thus predicting successful suppression of $\mathrm{Zn}(\mathrm{g})$ reoxidation by $\mathrm{CO}_{2}$ and $\mathrm{CO}$.

\section{INTRODUCTION}

Zinc is produced from the reduction of $\mathrm{ZnO}$ via either the electrolytic or the pyrometallurgical processing routes. ${ }^{1-3}$ In the dominating pyrometallurgical process, the Imperial Smelting Furnace (ISF) process, ${ }^{4} \mathrm{Zn}$ is extracted in a blast furnace by carbothermally reducing $\mathrm{ZnO}$ to form $\mathrm{Zn}(\mathrm{g})$ and $\mathrm{CO}$ in a highly endothermic reaction according to:

$$
\begin{aligned}
& \mathrm{ZnO}(\mathrm{s})+\mathrm{C}(\mathrm{s})=\mathrm{Zn}(\mathrm{g})+\mathrm{CO} \\
& \Delta H_{298 K}^{\circ}=239.9 \mathrm{~kJ} \mathrm{~mol}^{-1}
\end{aligned}
$$

The predominant reaction route is via the solidgas reaction:

$$
\begin{aligned}
& \mathrm{ZnO}(\mathrm{s})+\mathrm{CO}=\mathrm{Zn}(\mathrm{g})+\mathrm{CO}_{2} \\
& \Delta H_{298 \mathrm{~K}}^{\circ}=67.5 \mathrm{~kJ} \mathrm{~mol}^{-1}
\end{aligned}
$$

where $\mathrm{CO}$ is formed by the Boudouard reaction:

$$
\begin{aligned}
& \mathrm{CO}_{2}+\mathrm{C}(\mathrm{s})=2 \mathrm{CO} \\
& \Delta H_{298 \mathrm{~K}}^{\circ}=172.4 \mathrm{~kJ} \mathrm{~mol}^{-1}
\end{aligned}
$$

The heat required to drive the reaction is provided by the exothermic combustion of coke in preheated air entering into the furnace bosh.

Integration of concentrated solar energy into pyrometallurgical processes as an alternative energy source could significantly contribute to carbon dioxide mitigation in the production of zinc metal. ${ }^{5}$ The use of high-temperature solar process heat for the carbothermal reduction of $\mathrm{ZnO}$ has been previously proposed and experimentally demonstrated using a novel indirectly irradiated packed-bed solar reactor concept on a laboratory $\left(10 \mathrm{~kW}_{\mathrm{th}}\right)^{6,7}$ and pilot plant $\left(300 \mathrm{~kW}_{\text {th }}\right)$ scale. ${ }^{8,9}$ In addition to primary $\mathrm{Zn}$ production, zinc recovery from secondary sources via the carbothermal reduction of solarpurified Waelz oxide has also been experimentally investigated on a $10 \mathrm{~kW}_{\text {th }}$ scale. ${ }^{10}$ Furthermore, the 
use of methane as an alternative carbonaceous reducing agent for the co-production of $\mathrm{Zn}$ and synthesis gas by the combined reduction of $\mathrm{ZnO}$ and reforming of $\mathrm{CH}_{4}$ has been proposed and tested using a $5 \mathrm{~kW}_{\text {th }}$ vortex-flow solar reactor prototype. ${ }^{11}$

As the process temperatures in pyrometallurgical Zn production far exceed its boiling point $(1180 \mathrm{~K})$, it is produced in the vapor phase. Zinc vapor then has to be rapidly condensed (Eq. 4) to prevent the reoxidation reactions (Eqs. 5 and 6) to proceed:

$$
\begin{gathered}
\mathrm{Zn}(\mathrm{g})=\mathrm{Zn}(\mathrm{l}) \\
\mathrm{Zn}(\mathrm{g})+\mathrm{CO}_{2}=\mathrm{ZnO}(\mathrm{s})+\mathrm{CO} \\
\mathrm{Zn}(\mathrm{g})+\mathrm{CO}=\mathrm{ZnO}(\mathrm{s})+\mathrm{C}(\mathrm{s})
\end{gathered}
$$

The off-gas treatment system for the packed-bed solar reactor ${ }^{8,12}$ was specially designed for the production of fine zinc dust by quenching the flue gases with cold off-gas recycled back after zinc-dust separation in a cyclone. The solar-produced Zn dust allows for flexible chemical storage of solar energy and can be used for the production of high-purity $\mathrm{H}_{2}$ and $\mathrm{CO}$ as precursors to synthetic liquid fuels, ${ }^{13-16}$ or for electricity generation using Zn-air batteries, ${ }^{12,17}$ while the reoxidized $\mathrm{Zn}$ is recycled back to the solar reactor in the form of $\mathrm{ZnO}$, thus closing the thermochemical cycle. For the industrial application of zinc as a metal commodity, however, it is advantageous to condense zinc vapor to liquid rather than solid to avoid remelting the metal for subsequent refining and casting. In the conventional ISF process, the vapor is scrubbed from the furnace off-gas with lead droplets in a lead splash condenser. ${ }^{3}$ Zinc is thereby rapidly quenched and absorbed into molten lead, and reoxidation is mostly avoided. While several other concepts have been described in the literature,${ }^{18-21}$ some of which have been tested at pilot scale or commercially operated, the lead splash condenser remains the only commercial zinc condensation process in operation today. Adapting the conventional lead splash condenser in a solar thermochemical plant has several disadvantages however due to its mechanical complexity, its high operating and maintenance costs, and the health, safety, and environmental issues relating to the use of lead. ${ }^{22}$ Furthermore, because concentrated solar energy is used instead of coke combustion as the source of high-temperature process heat for driving the carbothermal reduction, the resulting off-gas has significantly lower $\mathrm{CO}_{2}$ content $\left(p_{\mathrm{CO}_{2}}<0.05 \mathrm{~atm} ; \frac{p_{\mathrm{CO}_{2}}}{p_{\mathrm{CO}}}<0.14\right)^{8}$ and consequently is less thermodynamically favorable toward zinc reoxidation, as it will be shown in the analysis that follows. This can facilitate the application of simpler zinc condenser concepts.
In this article, the development of an alternative zinc condenser to produce liquid zinc from the gas products evolving from the solar carbothermal reduction of $\mathrm{ZnO}$ is investigated. A comprehensive literature review of the kinetics of $\mathrm{Zn}(\mathrm{g})$ oxidation, and of metal vapor condensation concepts for the production of liquid metals, identified a potential alternative $\mathrm{Zn}$ condensation process. The technical feasibility of a proposed condensation process is assessed by the development of a transient model of simultaneous heat and mass transfer that links the competing condensation rates and kinetics of zinc vapor oxidation for solar reactor conditions. The condenser model allows the establishment of design specifications and operating conditions of a zinc condenser prototype.

\section{ZINC VAPOR OXIDATION AND CONDENSATION}

\section{Zinc Vapor Oxidation Studies and Kinetic Models}

The prevention of oxidizing conditions between a zinc producing reactor and the condensing unit is a major issue in $\mathrm{ZnO}$ carbothermal reduction processes such as the ISF process, and it would be similarly so for a solar zinc reactor-condenser process. As the gas temperature in the off-gas system decreases, the equilibrium of Eq. 5 is shifted to the product side favoring reoxidation of zinc vapor by $\mathrm{CO}_{2}$. At low temperatures, reoxidation can also proceed via reaction with $\mathrm{CO}$ (Eq. 6) to form $\mathrm{ZnO}$ and elemental carbon, but the reaction rates are apparently low as minimal carbon formation has been detected in operating industrial condensers. Zinc vapor oxidation reactions have been shown to proceed heterogeneously on a solid substrate or $\mathrm{ZnO}$ deposited on the reaction surface. ${ }^{22-32}$ Previous studies of $\mathrm{Zn}(\mathrm{g})$ oxidation by $\mathrm{CO}_{2}$ carried out at temperatures between $973 \mathrm{~K}$ and $1273 \mathrm{~K}$ and partial pressures of $\mathrm{Zn}(\mathrm{g})$ in the range of $0.01-$ $0.45 \mathrm{~atm}$ report reaction rates in the range of $10^{-9} \mathrm{~mol} \mathrm{~cm}^{-2} \mathrm{~s}^{-1}$ to $10^{-7} \mathrm{~mol} \mathrm{~cm} \mathrm{~cm}^{-2} \mathrm{~s}^{-1}$. The kinetics of $\mathrm{Zn}(\mathrm{g})$ oxidation in $\mathrm{CO}_{2}-\mathrm{CO}-\mathrm{N}_{2}$ mixtures were first studied for typical ISF gas compositions by Scott and Fray $^{24}$ at temperatures between $1073 \mathrm{~K}$ and $1203 \mathrm{~K}$ and $p_{\mathrm{Zn}(\mathrm{g})}$ up to $0.17 \mathrm{~atm}$. Zinc vapor was generated by passing a $\mathrm{CO}_{2}-\mathrm{CO}-\mathrm{N}_{2}$ gas mixture through a packed bed of $\mathrm{ZnO}$ pellets and was then flown through a $\mathrm{SiO}_{2}$ tube at a lower temperature, thereby allowing reoxidation to occur. The selected $\mathrm{Zn}(\mathrm{g})$ generation method, however, imposed a significant composition constraint $\left(p_{\mathrm{Zn}(\mathrm{g})} \leq p_{\mathrm{CO}_{2}}\right)$. The experimental data were fitted to a reversible, second-order rate expression:

$$
r^{\prime \prime}=k_{1} \cdot\left(p_{\mathrm{Zn}(\mathrm{g})} p_{\mathrm{CO}_{2}}-\frac{p_{\mathrm{CO}}}{K_{\mathrm{eq}}}\right)
$$

where $k_{1}$ is the forward reaction rate constant and $K_{\text {eq }}$ is the equilibrium constant for reaction (5). 
Clarke and Fray $^{26}$ studied the heterogeneous oxidation of $\mathrm{Zn}(\mathrm{g})$ in $\mathrm{CO}_{2}$-CO-Ar atmosphere at temperatures between $973 \mathrm{~K}$ and $1123 \mathrm{~K}$ and $p_{\mathrm{Zn}(\mathrm{g})}$ in the range of $0.01-0.1 \mathrm{~atm}$ using the same experimental setup. Two distinct reaction rate regimes were identified: (I) Below $1073 \mathrm{~K}$, coarse $\mathrm{ZnO}$ deposits were detected in the silica reactor tube and the reaction rate was proposed to be controlled by the excess $p_{\mathrm{Zn}(\mathrm{g})}$ :

$$
r^{\prime \prime}=k_{1} \cdot\left(p_{\mathrm{Zn}(\mathrm{g})}-p_{\mathrm{Zn}(\mathrm{g})}^{\mathrm{eq}}\right)
$$

and (II) for temperatures above $1073 \mathrm{~K}$ and $p_{\mathrm{CO}}>0.2 \mathrm{~atm}$, fine-grained $\mathrm{ZnO}$ prevailed and the surface desorption of $\mathrm{CO}$ was claimed to be the ratelimiting step of the reaction:

$$
r^{\prime \prime}=k_{1} \cdot\left(p_{\mathrm{Zn}(\mathrm{g})} p_{\mathrm{CO}_{2}}-\frac{p_{\mathrm{CO}}}{K_{\mathrm{eq}}}\right) \cdot\left(p_{\mathrm{CO}}-p_{\mathrm{CO}}^{\mathrm{eq}}\right)
$$

where $p_{\mathrm{CO}}^{\mathrm{eq}}$ is the partial pressure of carbon monoxide at chemical equilibrium. Investigations of the $\mathrm{Zn}(\mathrm{g})$ oxidation reaction over a wider range of compositions $\left(p_{\mathrm{Zn}(\mathrm{g})} \geq p_{\mathrm{CO}_{2}}\right)$, and at higher $p_{\mathrm{Zn}(\mathrm{g}) \text {, }}$ were facilitated by the modified reactor-flow apparatus used by Leonard ${ }^{28}$ and Stansbury. ${ }^{29}$ In their study, zinc vapor was generated by saturation of a CO stream passing over a silica boat of $\mathrm{Zn}(\mathrm{l})$ and then mixed with $\mathrm{CO}_{2}$ in a high-temperature zone to form a homogeneous reacting mixture. It was then passed through a low-temperature reactor tube where reoxidation occurred. For temperatures in the ranges of $1013-1273 \mathrm{~K}$ and $1243-1263 \mathrm{~K}$, and $\mathrm{Zn}(\mathrm{g})$ partial pressures of up to $0.28 \mathrm{~atm}$ and $0.22 \mathrm{~atm}$, respectively, the reaction was proposed to be independent of the partial pressure of the reacting gases and zero-order rate expressions were formulated for two temperature regimes:

$$
\begin{aligned}
& \ln r^{\prime \prime}=2.934 \times 10^{3}\left(\frac{1}{T+273}\right)-1.585 \\
& 765^{\circ} \mathrm{C} \leq T<883^{\circ} \mathrm{C} \\
& \ln r^{\prime \prime}=1.807 \times 10^{4}\left(\frac{1}{T+273}\right)-2.761 \\
& 883^{\circ} \mathrm{C} \leq T \leq 1000^{\circ} \mathrm{C}
\end{aligned}
$$

A major shortcoming of the experimental methodology is, however, the exclusion from the reaction rate analysis of the material deposited at the entrance region of the silica reactor tube. Furthermore, the possibility of $\mathrm{ZnO}$ forming by reaction (6) either in the vapor generation or the reaction zone is ignored by the use of $\mathrm{CO}$ as an inert carrier gas. Dell'Amico and $\mathrm{See}^{22,23}$ used an alternative $\mathrm{Zn}(\mathrm{g})$ generation technique to investigate the oxidation reaction in $\mathrm{CO}_{2}-\mathrm{CO}-\mathrm{N}_{2}$ atmosphere at compositions typical of those observed in the ISF off-gas system $\left(p_{\mathrm{Zn}(\mathrm{g}),}, p_{\mathrm{CO}_{2}}\right.$, and $p_{\mathrm{CO}}$ in the range of 0.04-0.12 atm, 0.10-0.17 atm, and 0.11-0.27 atm, respectively). A zinc-saturated $\mathrm{N}_{2}$ gas stream was produced by bubbling the gas through a $\mathrm{Zn}$ (l) bath and passed into the zinc vapor reactor held at the selected oxidation temperature (1023-1273 K). Coarse-grained $\mathrm{ZnO}$ deposits of similar morphology and reaction rates of the same order of magnitude $\left(10^{-7} \mathrm{~mol} \mathrm{~cm}^{-2} \mathrm{~s}^{-1}\right)$ as those obtained by Clarke $\mathrm{e}^{26}$ were reported. A semiempirical kinetic rate expression similar in form to Eq. 8 was proposed:

$$
r^{\prime \prime}=9.31 \times 10^{-4} \times e^{-5610 / T}\left(p_{\mathrm{Zn}(\mathrm{g})}-p_{\mathrm{Zn}(\mathrm{g})}^{\mathrm{eq}}\right)
$$

The work of Lewis and Cameron ${ }^{30,31}$ was motivated by the absence of a kinetic rate expression at higher $\mathrm{Zn}(\mathrm{g})$ partial pressures, as most of the existing studies were carried out at typical ISF gas compositions. In their study, zinc vapor was generated by saturation of an Ar stream flowing over a sealed crucible of $\mathrm{Zn}(1)$, and the oxidation was investigated at temperatures in the range of $1073-1273 \mathrm{~K}$ and partial pressures of $\mathrm{Zn}(\mathrm{g})$ between $0.18 \mathrm{~atm}$ and $0.45 \mathrm{~atm}$. The higher zinc content reflected gas compositions obtained during operation of plasma furnaces for the recovery of zinc from steel plant waste dusts. The reaction system was proposed to follow a three-step mechanism involving the competing reactions (5), (6), and (3), and a plug flow model was used for the formulation of an overall kinetic rate expression:

$$
r^{\prime \prime}=k_{1} \cdot p_{\mathrm{Zn}(\mathrm{g})} \cdot p_{\mathrm{CO}_{2}}+k_{2} \cdot p_{\mathrm{Zn}(\mathrm{g})} \cdot p_{\mathrm{CO}}
$$

where $k_{1}$ and $k_{2}$ are the forward rate constants of reactions (5) and (6), respectively. At high $p_{\mathrm{CO}} / p_{\mathrm{CO}_{2}}$ ratios, $\mathrm{Zn}(\mathrm{g})$ oxidation by $\mathrm{CO}$ prevailed in the system and the oxidation rate equation (Eq. 13) was reduced to the $k_{2} \cdot p_{\mathrm{Zn}(\mathrm{g})} \cdot p_{\mathrm{CO}}$ term, while at low $p_{\mathrm{CO}} / p_{\mathrm{CO}_{2}}$ ratios, the last term on the right-hand side (RHS) of Eq. 13 becomes negligible and the $\mathrm{ZnO}$ formation rate is proportional only to $p_{\mathrm{Zn}(\mathrm{g})}$ and $p_{\mathrm{CO}_{2}}$. Osborne et al. ${ }^{32}$ investigated the kinetics in a $\mathrm{Zn}-\mathrm{CO}-\mathrm{CO}_{2}-\mathrm{N}_{2}$ system at gas compositions reflecting the ISF conditions $\left(p_{\mathrm{Zn}(\mathrm{g})}, p_{\mathrm{CO}_{2}}\right.$, and $p_{\mathrm{CO}}$ in the range of $0.01-0.09 \mathrm{~atm}, 0-0.58 \mathrm{~atm}$, and $0-0.55$ atm, respectively) and at temperatures between $1003 \mathrm{~K}$ and $1023 \mathrm{~K}$. The method previously used by Leonard $^{28}$ and Stansbury ${ }^{29}$ was implemented for the generation of $\mathrm{Zn}(\mathrm{g})$. The reaction rate was found to increase with increasing partial pressure of $\mathrm{CO}$, despite it being a reaction product, leading to the conclusion that the rate-limiting step of the reaction is the autocatalytic oxidation of $\mathrm{Zn}(\mathrm{g})$ by $\mathrm{CO}$. A kinetic rate model was developed on a mechanistic basis. The proposed mechanism supported the adsorption of $\mathrm{Zn}(\mathrm{g})$ on the silica surface before it reacted, either directly or after forming a "Zn-CO" species, with $\mathrm{CO}_{2}$. The mechanism was claimed to support the autocatalytic character of the reaction 
and a corresponding reaction rate expression was formulated:

$$
r^{\prime \prime}=\frac{\left(k^{\prime}+k^{\prime \prime} \cdot p_{\mathrm{CO}}\right) \cdot\left(p_{\mathrm{Zn}(\mathrm{g})} p_{\mathrm{CO}_{2}}-\frac{p_{\mathrm{CO}}}{K_{\mathrm{eq}}}\right)}{\left(1+k^{\prime \prime \prime} \cdot p_{\mathrm{Zn}(\mathrm{g})}\right)}
$$

where $k^{\prime}, k^{\prime \prime}$, and $k^{\prime \prime \prime}$ are reaction rate constants of individual reaction steps and $K_{\text {eq }}$ is the equilibrium constant of reaction (5).

Figure 1 represents an equilibrium phase stability diagram for the carbothermal reduction of $\mathrm{ZnO}$, including the equilibrium $p_{\mathrm{CO}_{2}} / p_{\mathrm{CO}}$ ratio curves for the reactions $\mathrm{Zn}(\mathrm{g})+\mathrm{CO}_{2}=\mathrm{ZnO}(\mathrm{s})+$ $\mathrm{CO}, \mathrm{Zn}(\mathrm{l})+\mathrm{CO}_{2}=\mathrm{ZnO}(\mathrm{s})+\mathrm{CO}$ and $2 \mathrm{CO}=\mathrm{C}(\mathrm{s})+$ $\mathrm{CO}_{2}$ at selected values of $p_{\mathrm{Zn}(\mathrm{g})}$ and $p_{\mathrm{CO}}$. This diagram shows regions of stability for gas and pure solid phases of $\mathrm{ZnO}$ and carbon. The carbothermal reduction of $\mathrm{ZnO}$ proceeds in the region enclosed between the equilibrium $p_{\mathrm{CO}_{2}} / p_{\mathrm{CO}}$ curves for $\mathrm{Zn}(\mathrm{g})$ oxidation by $\mathrm{CO}_{2}$ and the reverse Boudouard reaction. Above the equilibrium curves of $\mathrm{Zn}(\mathrm{g})+\mathrm{CO}_{2}=$ $\mathrm{ZnO}(\mathrm{s})+\mathrm{CO}$, zinc vapor becomes unstable and oxidation is favored. A considerable increase in the reversion temperature of reaction (2) can be observed with increasing $p_{\mathrm{CO}_{2}} / p_{\mathrm{CO}}$ ratios at fixed $p_{\mathrm{Zn}(\mathrm{g})}$. Also indicated in Fig. 1 is a summary of the experimental conditions reported in $\mathrm{Zn}(\mathrm{g})$ oxidation studies and the solar reactor conditions for representative experimental runs at $\mathrm{ZnO}: \mathrm{C}$ molar ratios of $1: 0.8$ and $1: 0.9 .^{7,8,10}$ A typical range of $p_{\mathrm{CO}_{2}} / p_{\mathrm{CO}}$ ratios for the solar-driven process is $0.11-0.26$ because of the elimination of coke combustion. Most prior studies investigated $\mathrm{Zn}(\mathrm{g})$ oxidation at considerably higher ratios. Only Lewis and Cameron $^{30,31}$ and Osborne et al. ${ }^{32}$ conducted significant numbers of experiments at $p_{\mathrm{CO}_{2}} / p_{\mathrm{CO}}$ ratios coinciding with typical solar reactor atmospheres. Lewis and Cameron's work also considered $p_{\mathrm{Zn}(\mathrm{g})}$ in the range $0.18-0.45 \mathrm{~atm}$, thus reflecting typical $p_{\mathrm{Zn}(\mathrm{g})}$ values of $0.2 \mathrm{~atm}$ for a representative solar carbothermal reduction of $\mathrm{ZnO}$ at a $\mathrm{ZnO}: \mathrm{C}$ molar ratio of 1:0.8. ${ }^{10}$ Therefore, the reaction rate expression proposed by Lewis and Cameron (Eq. 13) is used in the current study.

\section{Zinc Vapor Condensation and Industrial Condensers}

Suppression of the thermodynamically favorable reoxidation reactions of $\mathrm{Zn}(\mathrm{g})$ by $\mathrm{CO}_{2}$ and $\mathrm{CO}$ can be attained by rapid cooling of the gaseous products. Historically, advancements in the $\mathrm{ZnO}$ reduction processes and increasing zinc production rates have been the main drivers for the development of novel $\mathrm{Zn}(\mathrm{g})$ condensation techniques. For example, the reaction products of a horizontal retort furnace process, ${ }^{1}$ comprising about $45 \% \mathrm{Zn}(\mathrm{g})$ and $55 \% \mathrm{CO}$, would condense on the wall of surface-type fireclay condensers. This early design was suitable for the low $\mathrm{Zn}$ production rates $(40 \mathrm{~kg} \mathrm{Zn} /$ day) of a horizontal retort, but major shortcomings arose

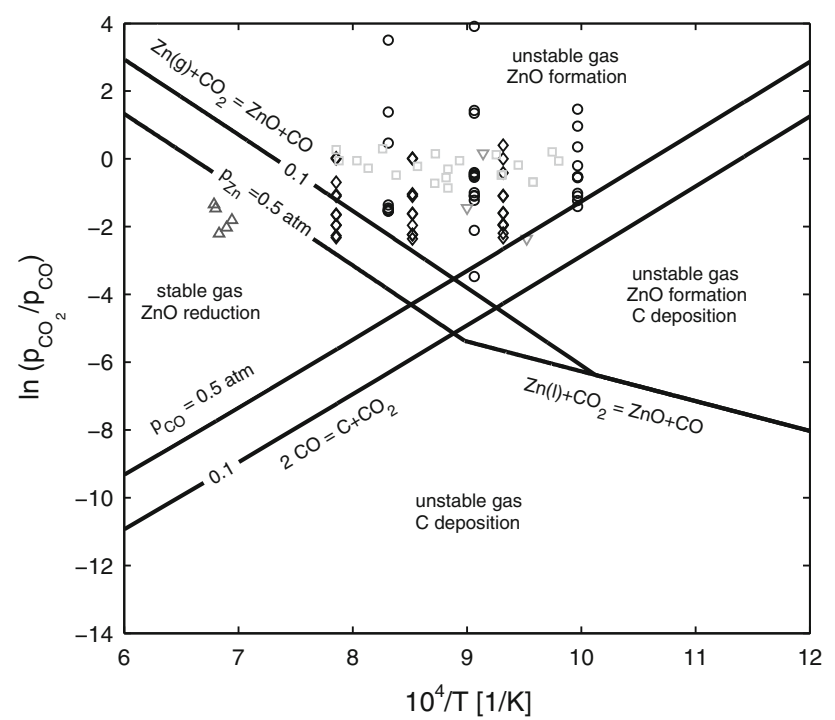

Fig. 1. Equilibrium phase stability diagram for the carbothermal reduction of $\mathrm{ZnO}$ at $p_{\mathrm{Zn}(\mathrm{g})}, p_{\mathrm{CO}}=0.1 \mathrm{~atm}$ and $0.5 \mathrm{~atm}$. Indicated are the experimental conditions reported in zinc vapor oxidation studies and the gas atmosphere for the packed-bed solar reactor outlet for representative experimental runs at $\mathrm{ZnO}: \mathrm{C}$ molar ratios of 1:0.8 and 1:0.9: Clarke and Fray ${ }^{26}(\nabla)$, Dell'Amico and $\operatorname{See}^{22}(\square)$, Lewis and Cameron $^{30,31}(\diamond)$, Osborne et al. ${ }^{32}(\bigcirc)$, Solar reactor ${ }^{7,8,10}(\triangle)$.

from the large number of condensers required and subsequently the high operational and maintenance costs. High-efficiency direct-contact condensation techniques became the center of interest for advanced $\mathrm{Zn}$ production technologies due to higher specific transfer areas, rapid transfer rates, relative simplicity of design, and lower maintenance costs. In the New Jersey Zinc Company's continuous vertical retort process ${ }^{33}$ with a capacity of $8 \mathrm{tpd} \mathrm{Zn}$, zinc was recovered from gas products of similar composition to a horizontal retort furnace by passing them countercurrently to a zinc splash condenser. In this arrangement, graphite rotors dipped into a $\mathrm{Zn}(\mathrm{l})$ pool created an intense shower of $\mathrm{Zn}(\mathrm{l})$ droplets to rapidly chill the furnace gases and absorb zinc vapor. The zinc pool was maintained at temperatures below $550^{\circ} \mathrm{C}$ through a water-cooled circulation system to keep equilibrium vapor losses to a minimum. Besides the New Jersey Zinc Process, zinc splash condenser technology has been adapted also in electrothermal ${ }^{34}$ and plasma-arc ${ }^{35}$ processes for zinc recovery from electric-arc furnace (EAF) dusts. Fuming of species other than zinc from the EAF feedstock however enhances the formation of heterogeneous condensation sites and, subsequently, contributes to fog and dross formation with a deleterious effect on zinc recovery. Another zinc condenser concept is the so-called "Wheaton-Najarian vacuum condenser" developed for the $2.44 \mathrm{~m}$ bore electrothermic zinc furnace at Josephtown Zinc Smelter with a capacity of $20-80$ tpd Zn. ${ }^{36,37}$ This condenser recovered zinc by bubbling a mixture of $\mathrm{Zn}(\mathrm{g})$ with noncondensable gases upwardly through a $\mathrm{Zn}(\mathrm{l})$ bath enclosed in a U-tube chamber 


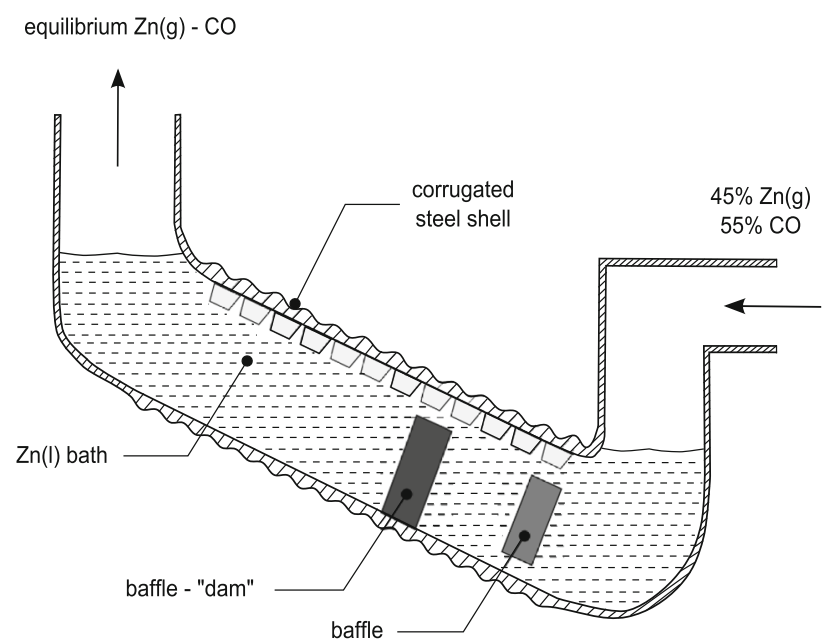

Fig. 2. Schematic of the Wheaton-Najarian vacuum condenser (based on drawings by Najarian ${ }^{21}$ ).

by suction. Brick baffles projecting normally to the inside of the roof of the condensing chamber were used to increase residence time and gas-liquid interfacial area through bubble breakup, as depicted in Fig. 2. Zinc that condensed and accumulated in the condenser was periodically tapped out. Condensation efficiency of the order of 97-98\% of theoretical was obtained when keeping the $\mathrm{Zn}(\mathrm{l})$ bath temperature in the range of $480-525^{\circ} \mathrm{C} .{ }^{19-21}$

The dominating pyrometallurgical $\mathrm{Zn}$ blast furnace process (ISF), however, required a condenser capable of handling high gas flows with low zinc concentration and of absorbing approximately 2.5 times the amount of heat absorbed by the WheatonNajarian (W-N) condenser per mole of $\mathrm{Zn}$ produced ${ }^{38}$ This is attributed to the heat liberated during cooling of an increased amount of noncondensable gases. ${ }^{4,38}$ A splash condenser was developed by the Imperial Smelting Company ${ }^{4}$ to recover zinc vapor flowing countercurrent to a liquid lead droplet shower produced by the rotation of steel impellers immersed in a bath of liquid lead. A zincrich phase is separated from the $\mathrm{Zn}-\mathrm{Pb}$ alloy leaving the condenser at $550^{\circ} \mathrm{C}$ with a $\mathrm{Zn}$ content of 2.26 wt.\% by exploiting an immiscibility gap of the $\mathrm{Zn}-\mathrm{Pb}$ binary system. The liquid stream is cooled down to $440^{\circ} \mathrm{C}$, where the solubility limit of $2.02 \mathrm{wt} . \%$ is reached, and liquid zinc separates as a layer over $\mathrm{Pb}(\mathrm{l})$. The liquid zinc is tapped out and the liquid lead is recirculated to the condenser inlet for recovery of fresh $\mathrm{Zn}(\mathrm{g})$. The lead splash condenser technology thus requires a continuous supply of large amounts of liquid lead ranging between 300 and 400 tonnes per tonne of $\mathrm{Zn}$ produced to operate. Although this condenser has high operational and maintenance costs, and it uses lead that suffers from critical health, safety, and environmental issues, it remains the only commercially used zinc condensation process. Besides primary zinc production processes, the ISP lead splash condenser technology has been used in processes for zinc recovery from steel plant dusts and zinc-containing slag. Recovery of 98.4 wt.\% pure zinc from lead-blast furnace slags using the Enviroplas process $^{39}$ has been successfully demonstrated at a 5.6 MVA scale. ${ }^{40}$ Several other condensation technologies have been proposed for the recovery of $\mathrm{Zn}(\mathrm{l})$ from a body of molten lead. ${ }^{41-45} \mathrm{~A}$ multicompartment combined $\mathrm{Zn}(\mathrm{l})$ - and $\mathrm{Pb}(\mathrm{l})$-splash condenser concept has been trialed to reduce the amount of $\mathrm{Pb}(\mathrm{l})$ recirculated. ${ }^{46}$ A lead-spray zinc condenser has been developed by SKF Plasma Technologies AB for zinc recovery from high-zinc-containing carbon steel dusts, but operation was terminated due to economic reasons after switching from processing carbon steel dusts to low-zinc-containing ( $<6 \mathrm{wt} . \%)$ alloy-steel dusts. Other zinc condensers such as of Solnordal et al. ${ }^{\text {is }}$ experimentally investigated the feasibility of using a fluidized bed of zircon sand to condense zinc from smelter off-gases as a solid. They reported the rapid cooling of the gas-vapor mixtures from about $1200-500^{\circ} \mathrm{C}$ within $8 \mathrm{~ms}$ and $\mathrm{Zn}$ recovery exceeding $90 \%$. The solid zinc condenser product, however, has disadvantages because it needs to be remelted for subsequent refining and casting of ingots.

In the solar reactor process, ${ }^{7,8}$ reaction gases also need to be rapidly quenched from the thermodynamically stable gas outlet temperature of $1473 \mathrm{~K}$ to temperatures where the kinetic rate of $\mathrm{Zn}$ reoxidation is slow. Major shortcomings for the application of the conventional lead splash condenser in a solar thermochemical plant arise from its size, mechanical complexity, and other issues described previously. Bubbling gas condensation through a bath of $\mathrm{Zn}(\mathrm{l})$ like the $\mathrm{W}-\mathrm{N}$ vacuum condenser has advantages of simplicity (no moving mechanical parts), intensity (smaller size), and no need of a secondary liquid metal phase. Solar reactor off-gas products are characterized by high $p_{\mathrm{CO}} / p_{\mathrm{CO}_{2}}$ ratios compared with those in an ISF, and the oxidation potential can be further decreased by operation with increased amount of carbon in the feedstock (ZnO:C molar ratios lower than 1:0.8) to produce gas compositions similar to the electrothermic furnace. A decrease in the flow rate of the inert carrier gas $\left(\mathrm{N}_{2}\right)$ allows for a significant reduction of the heat liberated during $\mathrm{Zn}(\mathrm{g})$ absorption and reduces the problem of heat dissipation that was reported to be the most significant shortcoming of the $\mathrm{W}-\mathrm{N}$ condenser. ${ }^{20,21}$ The W-N condenser design was not adopted for wide commercial application as it was initially developed for handling low gas volumes and gas atmospheres with low oxidation potential, and it was thus less suited to ISF conditions. However, with trends toward new technologies such as arc furnaces for zinc production and their formation of high concentration, lower volume $\mathrm{Zn}$ (g)-CO streams, molten zinc bath condensers should be reconsidered. This does also apply to future new zinc processes such as 


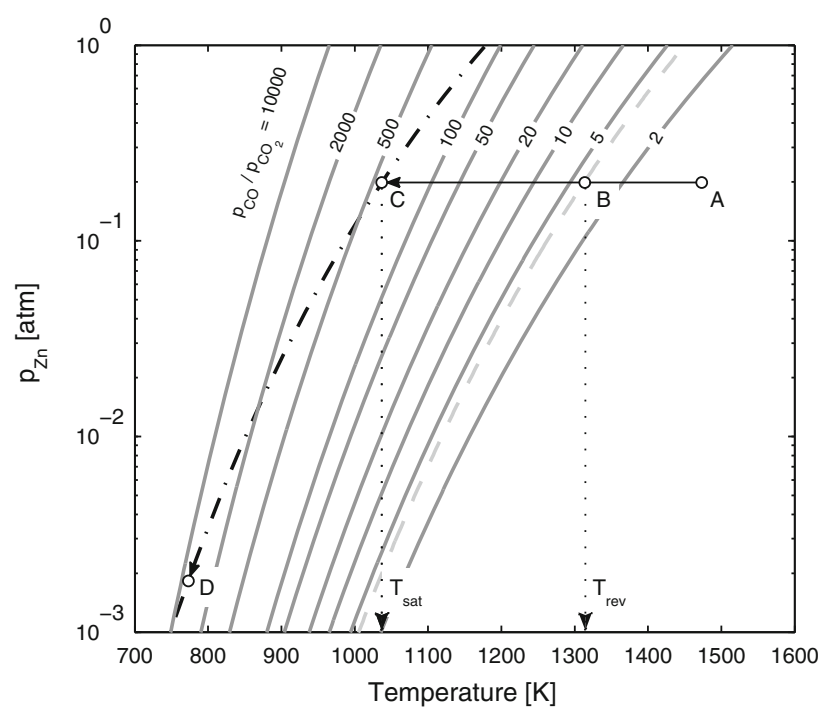

Fig. 3. Variation of the $\mathrm{Zn}$ vapor pressure and equilibrium $\mathrm{Zn}(\mathrm{g})$ partial pressure for reaction (5) at $p_{\mathrm{CO}} / p_{\mathrm{CO}_{2}}$ ratios in the range of $2-$ 10,000 along with points $(A, B, C, D)$ relevant to the operation of a $10 \mathrm{~kW}_{\text {th }}$ packed-bed solar reactor. ${ }^{10}$

the solar-driven thermochemical plants considered in this study. Therefore, the molten zinc bath condenser concept is chosen in the current study aiming at producing liquid $\mathrm{Zn}$ from the product gas evolving from the solar carbothermal reduction of $\mathrm{ZnO}$.

The operating conditions for the solar zinc reactor-condenser process can be characterized by a plot of the variation of $\mathrm{Zn}$ vapor pressure and equilibri$\mathrm{um} \mathrm{Zn}(\mathrm{g})$ partial pressure for reaction (5) at $p_{\mathrm{CO}} / p_{\mathrm{CO}_{2}}$ ratios in the range $2-10,000,{ }^{47}$ along with points relevant to the operation of a $10 \mathrm{~kW}_{\text {th }}$ packed-bed solar reactor, ${ }^{10}$ as shown in Fig. 3 . Typical solar reactor gas products containing $19.9 \%$ $\mathrm{Zn}(\mathrm{g})$ leave the reactor at $1473 \mathrm{~K}$ and a $p_{\mathrm{CO}} / p_{\mathrm{CO}_{2}}$ ratio of 3.8 (point A). This gas composition corresponds to the highest oxidation potential measured during typical experimental runs at $\mathrm{ZnO} \mathrm{C}$ molar ratios of 1:0.8 and 1:0.9 and is used as the base case scenario in the current study. Reoxidation of $\mathrm{Zn}(\mathrm{g})$ by $\mathrm{CO}_{2}$ is thermodynamically unfavorable until the reversion temperature of $1314 \mathrm{~K}$ (point $\mathrm{B}$ ) is reached, while condensation will commence only below the apparent saturation temperature of $1037 \mathrm{~K}$ (point C). Equilibrium condensation upon further cooling of the gases to the temperature of the $\mathrm{Zn}(\mathrm{l})$ bath at $773 \mathrm{~K}$ (point $\mathrm{D}$ ) follows the line CD. Thus, rapid quenching of the gas-vapor mixture should minimize the residence time and prevent $\mathrm{ZnO}$ formation in the temperature range between $1314 \mathrm{~K}$ and the kinetically unfavorable temperature of $773 \mathrm{~K}$ for the reversion reactions to occur.

\section{CONDENSATION MECHANISM OF VAPOR BUBBLES}

The key process in a molten zinc bath condenser is the condensation of $\mathrm{Zn}(\mathrm{g})$ from gas-vapor bubbles, the initial composition being that of the solar reactor process gas. The condensation and collapse of vapor bubbles in liquid baths has been extensively investigated at different degrees of subcooling, i.e., where the bath is maintained at temperatures below the apparent saturation temperature of the vapor. At high degrees of subcooling, bubble collapse is controlled by the inertia forces of the surrounding liquid and proceeds rapidly while no laminar boundary layer can be observed. ${ }^{48-51}$ Heat transfer through the vapor-liquid interface governs the process at moderate temperature differences. Heattransfer-controlled condensation of bubbles has been previously experimentally studied in miscible $^{52-58}$ and immiscible ${ }^{59}$ liquids. Bubble condensation Nusselt numbers have been derived capable of describing the dynamic nature of the liquid-vapor interface, as opposed to the case of convective heat transfer from a solid object. A critical evaluation of Nusselt correlations for vapor bubble condensation in subcooled flows is provided by Rabello and Buongiorno. ${ }^{60}$ The effect of noncondensable gases on the bubble collapse rate was investigated by Jacobs and Major ${ }^{61}$ and Ullmann and Letan. ${ }^{62}$ The dimensionless Jacob number, defined as the ratio of sensible to latent heat absorbed during the vaporliquid phase change, is used to define the limits of the inertia-controlled and heat-transfer-controlled regimes of condensation:

$$
J a=\frac{\rho_{1} \cdot c_{\mathrm{p}, 1} \cdot\left(T_{\mathrm{s}}^{*}-T_{\infty}\right)}{\rho_{v} \cdot \Delta h_{\mathrm{fg}}}
$$

where $T_{\mathrm{s}}^{*}$ is the apparent saturation temperature, $T_{\infty}$ is the temperature in the bulk liquid, $c_{\mathrm{p}, 1}$ is the specific heat capacity of the liquid, $\Delta h_{\mathrm{fg}}$ is the enthalpy of evaporation, and $\rho_{\mathrm{l}}$ and $\rho_{\mathrm{v}}$ are the density of the liquid and the vapor, respectively. Chen and Mayinger ${ }^{54}$ specified interfacial heat transfer as rate limiting up to $J a=80$, while a transition region of mixed effects was identified before entering the liquid inertia-controlled regime $(J a>100)$. Besides the temperature of the liquid bath, $J a$ varies with the partial pressure of the condensing vapor in the gas mixture when noncondensable gases are present. As the condensation proceeds, the fraction of noncondensable gases increases, thereby inducing a decrease in the apparent saturation temperature. Figure 4 shows the effect of the fraction of noncondensable gases on the apparent saturation temperature of $\mathrm{Zn}(\mathrm{g})$ and on the Jacob number during condensation of the gas-vapor mixture at selected temperatures of the $\mathrm{Zn}(1)$ bath. Inertia forces in the liquid phase govern condensation of a solar reactor gas-vapor mixture initially containing $19.9 \% \mathrm{Zn}(\mathrm{g})$ in a highly subcooled $\mathrm{Zn}(\mathrm{l})$ bath maintained at $500^{\circ} \mathrm{C}$, as indicated by the initial $J a=600$. Transition to the heat-transfer controlled regime is reached at $\Delta T_{\mathrm{sub}}=T_{\mathrm{s}}^{*}-T_{\infty}=55 \mathrm{~K}$, corresponding to $99.3 \%$ content of noncondensable gases in the gas-vapor mixture. 


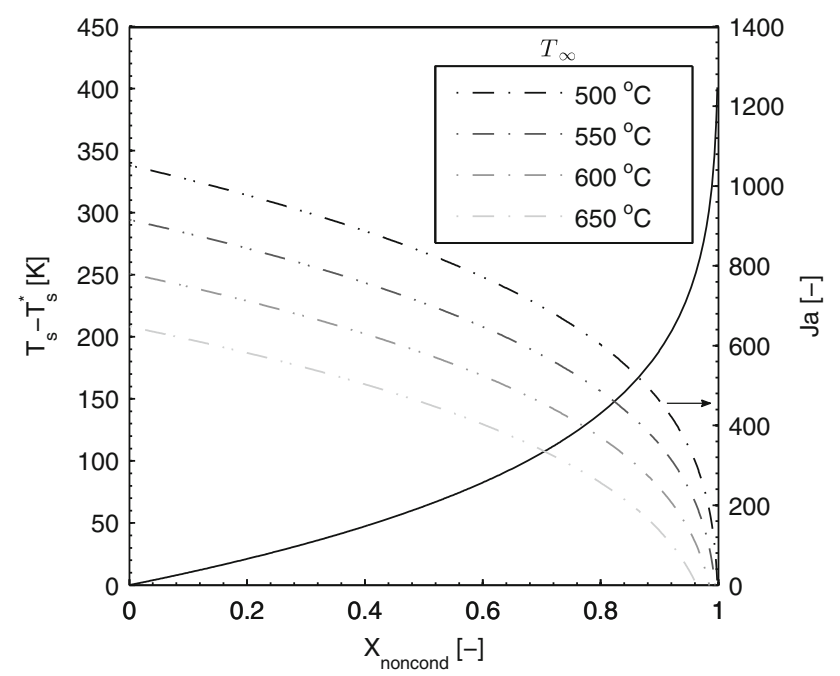

Fig. 4. Effect of the fraction of noncondensable gases on the apparent saturation temperature of $\mathrm{Zn}(\mathrm{g})$ and the Jacob number ( $\mathrm{Ja}$ ) for selected temperatures of the $\mathrm{Zn}(\mathrm{I})$ bath.

\section{FORMULATION OF HEAT- AND MASS-TRANSFER MODEL}

\section{Governing Equations}

A simplified, zero-dimensional transient heat and mass transfer model of a single bubble rising through a $\mathrm{Zn}(\mathrm{l})$ bath was developed to investigate the competing condensation rates and kinetics of oxidation of zinc vapor for a wide range of gas compositions. Neglect of the heat and mass transfer resistance within the bubble is justified by vigorous toroidal circulation of gas inside the bubble by virtue of the viscous drag of the outer fluid as described by Garner and Hammerton. ${ }^{63}$ In the case of condensing bubbles, circulation is further enhanced by the shrinking effect of the vapor-liquid interface. With the assumptions of (I) no interaction between individual bubbles, (II) constant liquid bulk temperature due to high thermal conductivity of the liquid phase, (III) constant relative velocity between bubbles and liquid, (IV) constant total pressure of 1 bar throughout, (V) reaction rate expressions as proposed by Lewis and Cameron for the reoxidation of $\mathrm{Zn}(\mathrm{g})$, and (VI) reactions occurring in the thermodynamically favorable regions according to Fig. 3, the mass conservation equation is:

$$
\frac{\mathrm{d} m_{\mathrm{b}}}{\mathrm{d} t}=M_{\mathrm{Zn}} \cdot r_{\mathrm{Zn}(\mathrm{g}), \text { cond }}
$$

where $m_{\mathrm{b}}$ is the mass of the bubble containing zinc vapor, noncondensable gases and the solid species involved in the reactions (3), (5), and (6). The RHS term accounts for the mass of the condensate exchanged with the liquid bath defined by the condensation molar source multiplied by the molar weight of $\mathrm{Zn}$. The conservation equation of species $k$ in the bubble is: ${ }^{64}$

$$
\frac{\mathrm{d} m_{k}}{\mathrm{~d} t}=M_{k} \cdot r_{k}
$$

where $r_{k}=\sum_{j=1}^{3} r_{k, j}$ for $\mathrm{CO}, \mathrm{CO}_{2}, \mathrm{~N}_{2}, \mathrm{ZnO}$, and $\mathrm{C}$, and $r_{\mathrm{Zn}(\mathrm{g})}=\sum_{j=1}^{3} r_{\mathrm{Zn}(\mathrm{g}), j}+r_{\mathrm{Zn}(\mathrm{g}), \text { cond }}$ for $\mathrm{Zn}(\mathrm{g})$. The summation accounts for the mass change of species $k$ at the three individual steps involved in the $\mathrm{Zn}(\mathrm{g})$ oxidation reaction mechanism. The energy conservation equation expressed in terms of the sensible enthalpy $h_{\mathbf{s}}$ is: ${ }^{65}$

$$
\begin{aligned}
& m_{\mathrm{b}} c_{\mathrm{p}, \mathrm{eff}} \frac{\mathrm{d} T_{\mathrm{b}}}{\mathrm{d} t}+\sum_{k=1}^{6} r_{k} h_{\mathrm{s}, \mathrm{k}}=-h A_{\mathrm{b}}\left(T_{\mathrm{b}}-T_{\mathrm{Zn}(\mathrm{l})}\right) \\
& -r_{\mathrm{Zn}(\mathrm{l}), \text { cond }} h_{\mathrm{s}, \mathrm{Zn}(\mathrm{l})}+r_{\mathrm{Zn}(1), \mathrm{cond}} \Delta h_{g f}^{o}+\sum_{j=1}^{3} r_{j} \Delta h_{\mathrm{rxn}, j}^{o}
\end{aligned}
$$

where $c_{\mathrm{p} \text {,eff }}$ is the effective specific heat capacity, $T_{\mathrm{b}}$ is the temperature of the gas-vapor mixture, $h_{\mathrm{s}, k}$ is the sensible enthalpy of species $k, h$ is the convective heat-transfer coefficient, $r_{\mathrm{Zn}(1) \text {, cond }}$ is the molar production rate of liquid zinc, and $A_{\mathrm{b}}$ is the interfacial area calculated assuming a spherical bubble. The second term on the RHS of Eq. 18 represents the energy of mass exchanged with the liquid phase, while the two last terms denote the heat of condensation and the heat of reactions (5), (6), and (3) at standard conditions. Different correlations are applied for the interfacial heat-transfer coefficient depending on the physical phenomena taking place and the controlling mechanism of condensation. The Hughmark correlation, ${ }^{66}$ initially developed for flows around rigid spheres, is employed during cooling of the gas-vapor mixture to the apparent saturation temperature (line segment AC in Fig. 3):

$$
h=\left\{\begin{array}{c}
\frac{k_{1}}{D_{\mathrm{b}}}\left(2+0.6 \operatorname{Re}_{\mathrm{b}}^{1 / 2} \operatorname{Pr}_{1}^{1 / 3}\right) 0 \leq \operatorname{Re}_{\mathrm{b}} \leq 776 \\
\frac{k_{1}}{D_{\mathrm{b}}}\left(2+0.27 \operatorname{Re}_{\mathrm{b}}^{0.62} \operatorname{Pr}_{1}^{1 / 3}\right) \operatorname{Re}_{\mathrm{b}} \geq 776
\end{array}\right.
$$

where $\operatorname{Re}_{\mathrm{b}}=\frac{u_{\mathrm{rel}} D_{\mathrm{b}}}{r_{\mathrm{j}}}$ is the bubble Reynolds number, $u_{\text {rel }}$ is the relative velocity between gas and liquid, $D_{\mathrm{b}}$ is the bubble diameter, and $v_{\mathrm{l}}, k_{\mathrm{l}}$, and $\operatorname{Pr}_{1}$ represent the kinematic viscosity, thermal conductivity, and Prandtl number of the liquid, respectively. In the inertia-controlled regime the kinetic theory of gases can be used for the vaporliquid interface. The heat-transfer coefficient is then obtained using the Hertz-Knudsen-Shrage equation $^{67}$ corrected for a curved interface: ${ }^{68,69}$

$$
\begin{aligned}
h= & \frac{4}{4-3 K_{c}}\left(\frac{1}{2 \pi M_{\mathrm{Zn}} R}\right)^{1 / 2}\left\{K_{\mathrm{C}} \frac{p_{\mathrm{Zn}(\mathrm{g})}}{T_{\mathrm{b}}^{1 / 2}}-K_{E} \frac{p_{\mathrm{Zn}(\mathrm{l})}}{T_{\mathrm{Zn}(1)}^{1 / 2}}\right\} . \\
& \frac{\Delta h_{g f}}{\left(T_{\mathrm{b}}-T_{\mathrm{Zn}(\mathrm{l})}\right)}
\end{aligned}
$$


where $p_{\mathrm{Zn}(1)}$ is the saturation partial pressure of zinc vapor at $T_{\mathrm{Zn}(1)}$, and $K_{\mathrm{C}}$ and $K_{\mathrm{E}}$ are the condensation and evaporation coefficients. $K_{\mathrm{C}}$ is defined as the ratio of incident vapor molecules absorbed by the liquid phase to the molecules impinging onto the liquid-vapor interface, and $K_{\mathrm{E}}$ is the ratio of molecules entering the vapor phase to the molecules leaving the liquid phase. The simplification $K_{\mathrm{C}}=K_{\mathrm{E}}=0.96$ is used as was measured for the condensation coefficient at a solid-liquid $\mathrm{Zn}$ interface by Rapp et al. ${ }^{70}$

In the heat-transfer controlled condensation regime the following correlation proposed by Chen and Mayinger ${ }^{54}$ for $\operatorname{Re}_{\mathrm{b}} \leq 10,000$ and $2 \leq \operatorname{Pr}_{1} \leq 15$ is implemented:

$$
h=\frac{k_{1}}{D_{\mathrm{b}}}\left(0.185 \operatorname{Re}_{\mathrm{b}}^{0.7} \operatorname{Pr}_{1}^{1 / 2}\right)
$$

\section{Numerical Method and Code Verification}

An adaptive time-stepping technique is employed for the entire calculation procedure to enhance the robustness of the code and to achieve the desired solution accuracy with minimum computational effort. ${ }^{71}$ The automatic control of the time step is based on the estimation of the local truncation error associated with the time integration scheme. Considering an ordinary differential equation of the form:

$$
\frac{\mathrm{d} y}{\mathrm{~d} t}=F(t, y(t))
$$

an estimate of the local error $\tau$ at $t+\Delta t$ is obtained by applying the explicit Euler integration scheme using two time steps of different size, $\Delta t$ and $\Delta t / 2$ :

$$
\begin{gathered}
y_{t+\Delta t}=y_{t}+\Delta t \cdot F\left(t, y_{t}\right) \\
y_{t+\frac{\Delta t}{2}}=y_{t}+\frac{\Delta t}{2} \cdot F\left(t, y_{t}\right) \\
y_{t+\Delta t}^{\prime}=y_{t+\frac{\Delta t}{2}}+\frac{\Delta t}{2} \cdot F\left(t+\frac{\Delta t}{2}, y_{t+\frac{\Delta t}{2}}\right) \\
\tau_{t+\Delta t}=y_{t+\Delta t}^{\prime}-y_{t+\Delta t}
\end{gathered}
$$

The local error estimate is compared with a prescribed local error tolerance value $\tau_{\mathrm{TOL}}$ to either accept the current time step size or calculate the optimal time step $\Delta t^{*}$ :

$$
\Delta t *=0.9 \Delta t \frac{\tau_{\mathrm{TOL}}}{\tau_{t+\Delta t}}
$$

where 0.9 is a damping factor used to decrease the risk of rejection of the next time step. The local error tolerance value $\tau_{\mathrm{TOL}}$ is set equal to $5 \times 10^{-3}$ to ensure an acceptable accuracy of the solution with minimum computational effort. A study has been conducted to facilitate the selection of an appropriate value for the local error tolerance. Values below $10^{-2}$ have been shown to have a negligible effect on the solution accuracy. The corresponding plots are omitted for brevity.

The correct implementation of the numerical method has been assessed by performing a code verification study using the method of manufactured solutions. ${ }^{72}$ The assessment of the implementation is based on conducting a time-step refinement study in which the global error between the numerical solution and an "exact" manufactured solution is evaluated as the time step size is reduced. Thus, the code verification study has been conducted using a fixed time step size for the entire calculation procedure rather than an adaptive time step. The order of accuracy of the numerical method is determined from the rate at which the numerical solution tends to the "exact" manufactured solution. A correct implementation of the numerical method can be ensured when the actual order of accuracy for the individual terms in the governing equations approaches the nominal order of accuracy in the asymptotic range of convergence. For Eqs. 16-18, the actual order of accuracy approaches unity with decreasing time step size when applying the explicit Euler integration scheme, which indicates the correct implementation of the numerical method. The corresponding plots are omitted for brevity.

\section{RESULTS AND DISCUSSION}

In the following, the modeling results are described and discussed based on process conditions typical for the solar carbothermal $\mathrm{ZnO}$ reduction process.

\section{Results}

The temperature of the $\mathrm{Zn}(\mathrm{l})$ bath, the initial bubble diameter, the relative velocity between bubbles and liquid, as well as the fraction of noncondensable gases in the vapor-gas mixture are the main parameters affecting the total process time and condensation efficiency. Bath temperatures in the range of $500-650^{\circ} \mathrm{C}$ were investigated to allow efficient operation of the condenser while maintaining an adequate margin above the melting point to avoid solidification. Although the majority of studies on gas bubbles rising in liquid baths involve sparging or submerged lance injection, these techniques entail a high risk of clogging by solid products formed during $\mathrm{Zn}(\mathrm{g})$ reoxidation and are not considered practical for the zinc vapor reactor application. Pumping or suction of the vapor-gas mixture through a $\mathrm{Zn}(\mathrm{l})$ bath in a similar manner to 

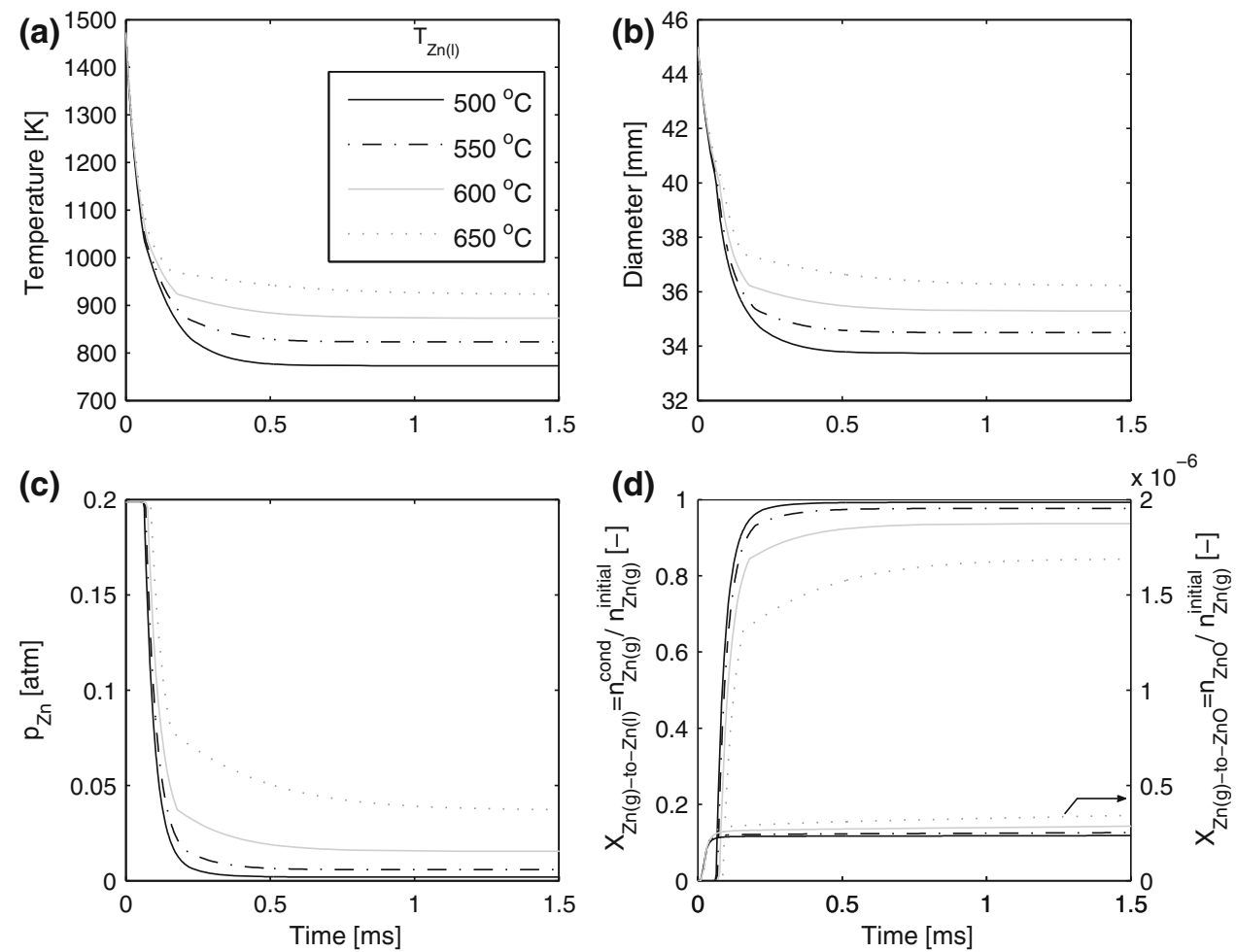

Fig. 5. Variation of the (a) gas temperature, (b) bubble diameter, (c) $\mathrm{Zn}(\mathrm{g})$ partial pressure, and (d) chemical conversion of $\mathrm{Zn}(\mathrm{g})$-to- $\mathrm{Zn}(\mathrm{l})$ and $\mathrm{Zn}(\mathrm{g})$-to-ZnO for a bubble with an initial diameter of $45 \mathrm{~mm}$ and $80.1 \%$ noncondensable gases rising at $0.11 \mathrm{~m} \mathrm{~s}^{-1}$ in a $\mathrm{Zn}(\mathrm{l})$ bath maintained in the temperature range of $500-650^{\circ} \mathrm{C}$.

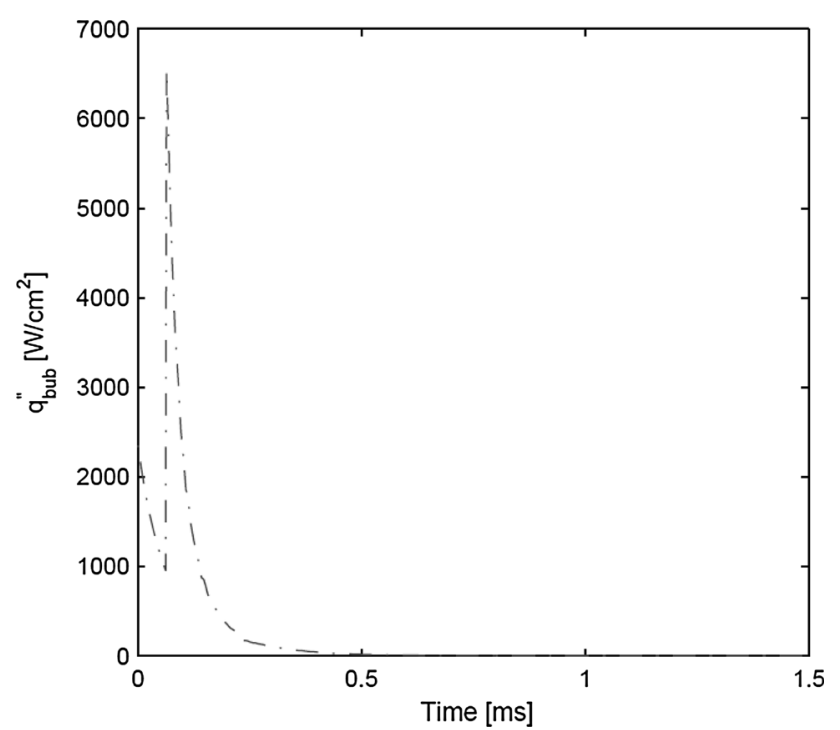

Fig. 6. Heat flux from a bubble with an initial diameter of $45 \mathrm{~mm}$ and $80.1 \%$ noncondensable gases rising at $0.11 \mathrm{~m} \mathrm{~s}^{-1}$ in a $\mathrm{Zn}(\mathrm{l})$ bath maintained at $500^{\circ} \mathrm{C}$.

the $\mathrm{W}-\mathrm{N}$ vacuum condenser favors the formation of large gas bubbles. In line with the findings of Haberman and Morton, ${ }^{73}$ bubble diameters in the range of $10-80 \mathrm{~mm}$ are considered in the current study.

Haberman and Morton ${ }^{73}$ further identified increasing terminal rise velocities with increasing bubble size. For bubbles in the $10-80 \mathrm{~mm}$ range, the terminal velocity is independent of the properties of the surrounding liquid and can be obtained according to: ${ }^{73}$

$$
u_{\text {term }}=1.02 \sqrt{g \frac{D_{\mathrm{b}}}{2}}
$$

Relative velocities between bubbles and liquid in the range between $0.02 \mathrm{~m} \mathrm{~s}^{-1}$ and $0.2 \mathrm{~m} \mathrm{~s}^{-1}$, the terminal rise velocity for a $10 \mathrm{~mm}$-diameter bubble, were therefore studied in the current work. To investigate the effect of the presence of noncondensable gases in the mixture, the initial fractions of noncondensable gases were varied between 0.535 and 0.801 . These conditions are typical for the $10 \mathrm{~kW}_{\text {th }}$ packed-bed solar reactor ${ }^{10}$ and correspond in this experimental setup to inert carrier gas $\left(\mathrm{N}_{2}\right)$ mass flow rates between 0.5 and $5 \mathrm{~L}_{\mathrm{N}}$ min $^{-1}$ (liters at normal conditions; mass flow rates are calculated at $273 \mathrm{~K}$ and 1 bar), respectively. These conditions were used as the basis for modeling.

The variation of the gas temperature, the bubble diameter, the $\mathrm{Zn}(\mathrm{g})$ partial pressure, and the chemical conversions of $\mathrm{Zn}(\mathrm{g})$ to $\mathrm{Zn}(\mathrm{l})$ and $\mathrm{ZnO}$ as a function of time is shown in Fig. 5a-d, respectively, for a bubble with an initial diameter of $45 \mathrm{~mm}$ and $80.1 \%$ noncondensable gases rising at $0.11 \mathrm{~m} \mathrm{~s}^{-1}$ in a $\mathrm{Zn}(\mathrm{l})$ bath at temperatures in the range of 

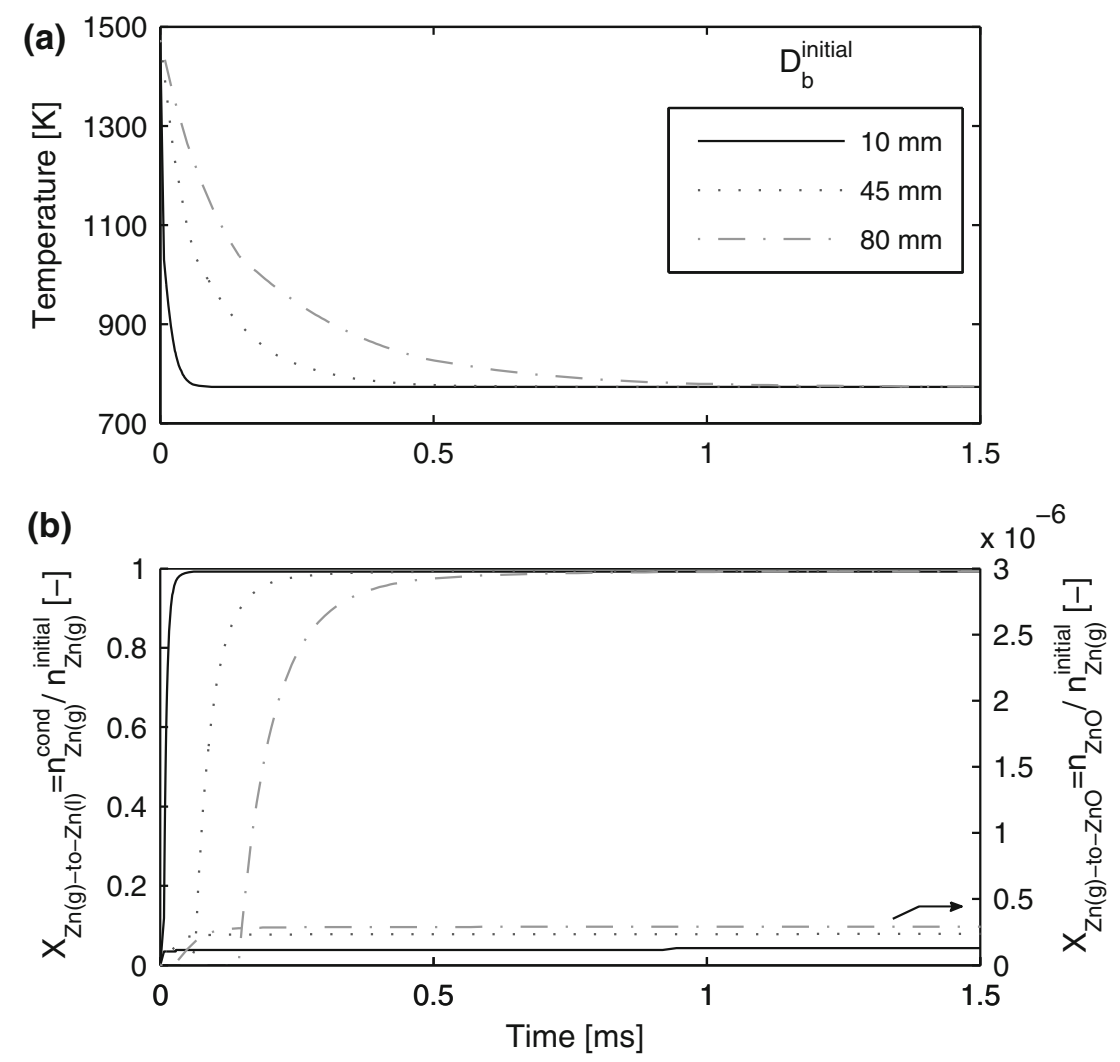

Fig. 7. Effect of the initial bubble diameter on the heat and mass transfer rates as illustrated by the variation of temperature and chemical conversions for a bubble with an initial content of $80.1 \%$ noncondensable gases rising at $0.11 \mathrm{~m} \mathrm{~s}^{-1}$ in a $\mathrm{Zn}(\mathrm{l})$ bath maintained at $500^{\circ} \mathrm{C}$.

$500-650^{\circ} \mathrm{C}$. The gas temperature drops monotonically to reach the corresponding $\mathrm{Zn}(\mathrm{l})$ bath temperature within less than $1 \mathrm{~ms}$. Higher heattransfer rates are observed with decreasing bath temperatures owing to the higher thermodynamic driving forces. The obvious change in curvature in the temperature curves, which for $T_{\mathrm{Zn}(1)}=600^{\circ} \mathrm{C}$ is clearly identifiable at $0.2 \mathrm{~ms}$, is attributed to the transition from inertia-controlled to heat-transfercontrolled condensation regimes. A notable increase in the final bubble diameter from $D_{\mathrm{b}}=33.7 \mathrm{~mm}$ at $T_{\mathrm{Zn}(1)}=500^{\circ} \mathrm{C}$ to $D_{\mathrm{b}}=36.2 \mathrm{~mm}$ at $T_{\mathrm{Zn}(1)}=650^{\circ} \mathrm{C}$ is obtained due to the nonlinear increase of the equilibrium $\mathrm{Zn}(\mathrm{g})$ losses with temperature, as indicated in Fig. 5b and c. Figure 5d reveals that rapid quenching of the gas-vapor mixture to temperatures, where the formation of $\mathrm{ZnO}$ is kinetically hindered, enables the suppression of the reversion reactions of $\mathrm{Zn}(\mathrm{g})$ by $\mathrm{CO}_{2}$ and $\mathrm{CO}$ and facilitates high $\mathrm{Zn}(\mathrm{l})$ yields. Conversion of $\mathrm{Zn}(\mathrm{g})$ to $\mathrm{Zn}(\mathrm{l})$ increases from 0.845 at $T_{\mathrm{Zn}(1)}=650^{\circ} \mathrm{C}$ to 0.992 at $500^{\circ} \mathrm{C}$, whereas only a small fraction of $\mathrm{Zn}(\mathrm{g})$ entering the condenser is predicted to form $\mathrm{ZnO}$. The fraction of reversion $X_{\mathrm{Zn}(\mathrm{g}) \text {-to-ZnO }}$ is in the range of $2.4 \times 10^{-7}$ to $3.6 \times 10^{-7}$.

The heat flux from a bubble with an initial diameter of $45 \mathrm{~mm}$, and $80.1 \%$ noncondensable gases, rising at $0.11 \mathrm{~m} \mathrm{~s}^{-1}$ in a $\mathrm{Zn}(\mathrm{l})$ bath maintained at $500^{\circ} \mathrm{C}$ is shown in Fig. 6. The initial drop in the heat flux curve corresponding to cooling without condensation (line segment AC in Fig. 3) is followed by a heat flux peak of $6500 \mathrm{~W} \mathrm{~cm}^{-2}$ as the gasvapor mixture reaches the apparent saturation temperature of $1037 \mathrm{~K}$ and condensation commences. The notable decrease in the heat flux at temperatures below $1037 \mathrm{~K}$ is attributed to the decreasing partial pressure of $\mathrm{Zn}(\mathrm{g})$ and, hence, mass transfer driving force. Large amounts of heat are released from the condensing bubble surface as a result of both the rapid $\mathrm{Zn}(\mathrm{g})$ condensation and the high enthalpy of condensation. Heat flux values shown in Fig. 6 are comparable to fluxes of $1896-3564 \mathrm{~W} \mathrm{~cm}^{-2}$ reported in Gunther's cinematographic study ${ }^{74}$ of the mechanism of highly subcooled $\left(\Delta T_{\text {sub }}=245-256^{\circ} \mathrm{C}\right)$ nucleate boiling of water.

The effect of the initial bubble diameter on the heat and mass transfer rates for a bubble with an initial content of $80.1 \%$ noncondensable gases rising at $0.11 \mathrm{~m} \mathrm{~s}^{-1}$ in a bath maintained at $500^{\circ} \mathrm{C}$ is shown in Fig. 7 by plotting the variation of the gas temperature and chemical conversions as a function of time. An increase of the initial diameter from $10 \mathrm{~mm}$ to $80 \mathrm{~mm}$ induces a two orders of magnitude increase in the time required to reach the apparent saturation temperature and thermal equilibrium due to the decrease of the surface-area-to-volume ratio. For a 10 -mm-diameter bubble, condensation commences after $7 \mu$ s to reach a $X_{\mathrm{Zn}(\mathrm{g}) \text {-to-Zn(1) }}$ of 0.992 

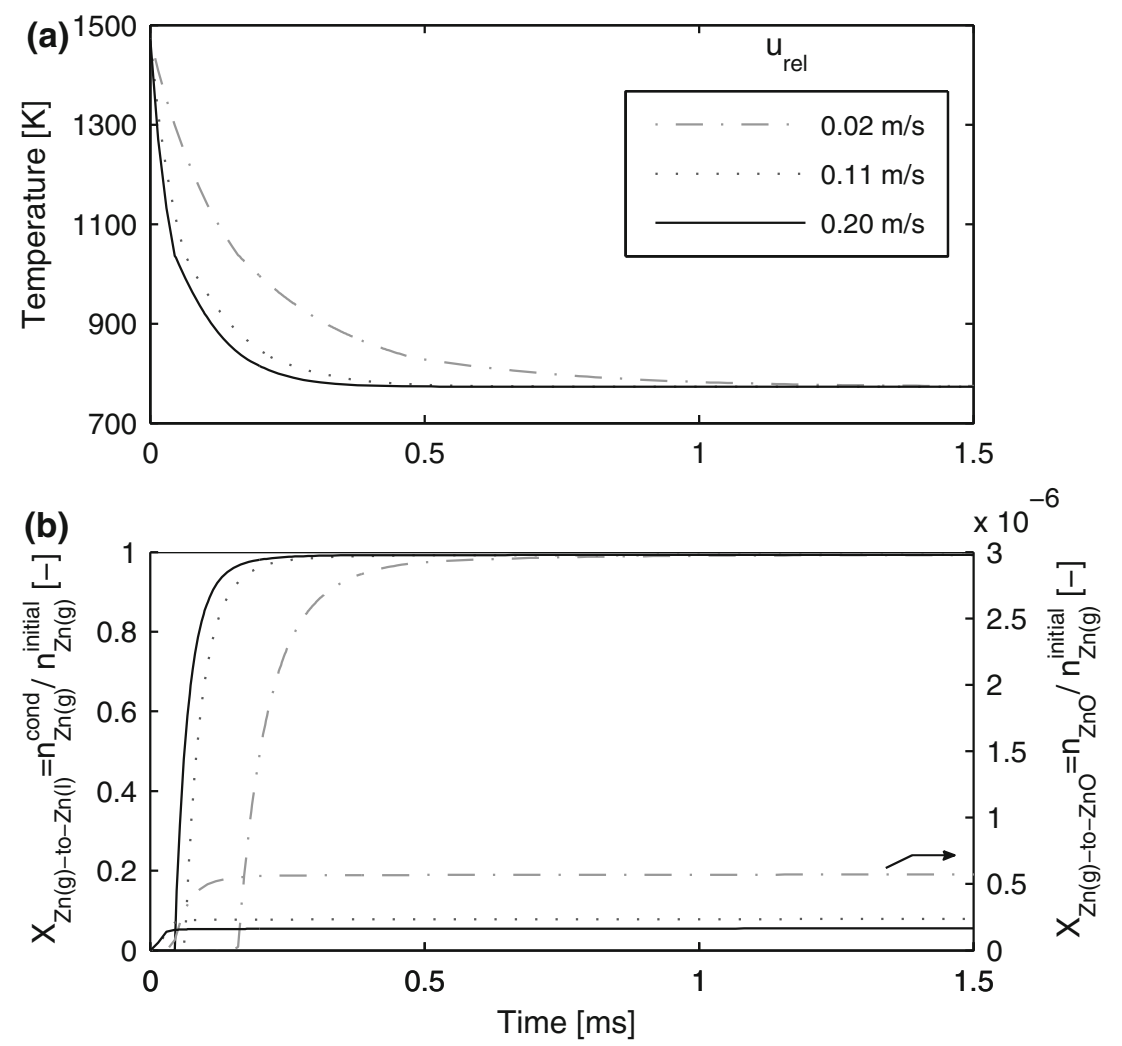

Fig. 8. Effect of the relative velocity between gas bubbles and liquid on the heat and mass transfer rates as illustrated by the variation of temperature and chemical conversions for a bubble with an initial diameter of $45 \mathrm{~mm}$ and initial content of $80.1 \%$ noncondensable gases rising in a $\mathrm{Zn}(\mathrm{I})$ bath maintained at $500^{\circ} \mathrm{C}$.

after $60 \mu \mathrm{s}$, whereas a 80-mm-diameter bubble requires $1.12 \mathrm{~ms}$ to reach the same conversion. Lower heat-transfer rates with increasing bubble diameter result in an increase of the asymptotic $X_{\mathrm{Zn}(\mathrm{g})-\mathrm{to}-\mathrm{ZnO}}$ conversion from $1.3 \times 10^{-7}$ to $2.9 \times 10^{-7}$ due to the longer residence time of the gas-vapor mixture at temperatures favoring $\mathrm{ZnO}$ formation. An increase in the gas-liquid relative velocity results in similar trends as a decrease in the initial bubble diameter, as shown in Fig. 8 for a bubble with an initial diameter of $45 \mathrm{~mm}$. An order of magnitude increase in the relative velocity reduces the time required to reach a $X_{\mathrm{Zn} \text { (g)-to-Zn(l) }}$ of 0.992 from $1.32 \mathrm{~ms}$ to $0.39 \mathrm{~ms}$ due to the enhanced heat and mass transfer, whereas the asymptotic $X_{\mathrm{Zn}(\mathrm{g})-\mathrm{to}-\mathrm{ZnO}}$ conversion decreases from $5.7 \times 10^{-7}$ to $1.7 \times 10^{-7}$.

Figure 9 shows the effect of the molar fraction of noncondensable gases on the time variation of the bubble diameter and the chemical conversions of $\mathrm{Zn}(\mathrm{g})$ to $\mathrm{Zn}(\mathrm{l})$ and $\mathrm{ZnO}$ for a bubble with an initial diameter of $45 \mathrm{~mm}$, rising at $0.11 \mathrm{~m} \mathrm{~s}^{-1}$ in a $\mathrm{Zn}(1)$ maintained at $500^{\circ} \mathrm{C}$. The fraction of noncondensable gases in the bubble controls the thermodynamic driving force in the condensation process by affecting the $\mathrm{Zn}(\mathrm{g})$ partial pressure and, consequently, the apparent saturation temperature. Thus, higher fractions of noncondensable gases induce a decrease in the shrinking rate of the bubble, as depicted in Fig. 9a. The increase of the final bubble diameter from $29.5 \mathrm{~mm}$ to $33.7 \mathrm{~mm}$ with increasing initial content of noncondensable gases is attributed to the volume occupied by the additional amount of $\mathrm{N}_{2}$ in the gas-vapor mixture. The fraction of noncondensable gases exhibits a negligible effect on the $X_{\mathrm{Zn}(\mathrm{g}) \text {-to-Zn(l) }}$ conversion (Fig. 9b), which varies between 0.992 and 0.998 at initial contents of $80.1 \%$ and $53.5 \%$ noncondensable gases, respectively. In contrast, $X_{\mathrm{Zn} \text { (g)-to-ZnO conversion increases }}$ by an order of magnitude from $2.37 \times 10^{-7}$ to $1.03 \times 10^{-6}$ at a lower content of noncondensable gases due to the first-order dependence of the reversion reaction rates on the partial pressures of $\mathrm{Zn}(\mathrm{g}), \mathrm{CO}$, and $\mathrm{CO}_{2}$.

The effect of liquid bath temperature and fraction of noncondensable gases on the $X_{\mathrm{Zn}(\mathrm{g}) \text {-to-Zn(1) }}$ conversion is shown in Fig. 10. The notable decrease in the $X_{\mathrm{Zn}(\mathrm{g}) \text {-to-Zn(l) }}$ conversion with increasing liquid zinc bath temperature is attributed to the nonlinear increase of the equilibrium vapor losses with temperature. The variation of the $X_{\mathrm{Zn} \text { (g)-to- } \mathrm{Zn}(\mathrm{l})}$ conversion between 0.992 and 0.998 at initial molar contents of $80.1 \%$ and $53.5 \%$ noncondensable gases illustrates a negligible effect of the fraction of noncondensable gases on the condensation efficiency for a highly subcooled liquid bath maintained at $500^{\circ} \mathrm{C}$. On the contrary, an increase in the content of 

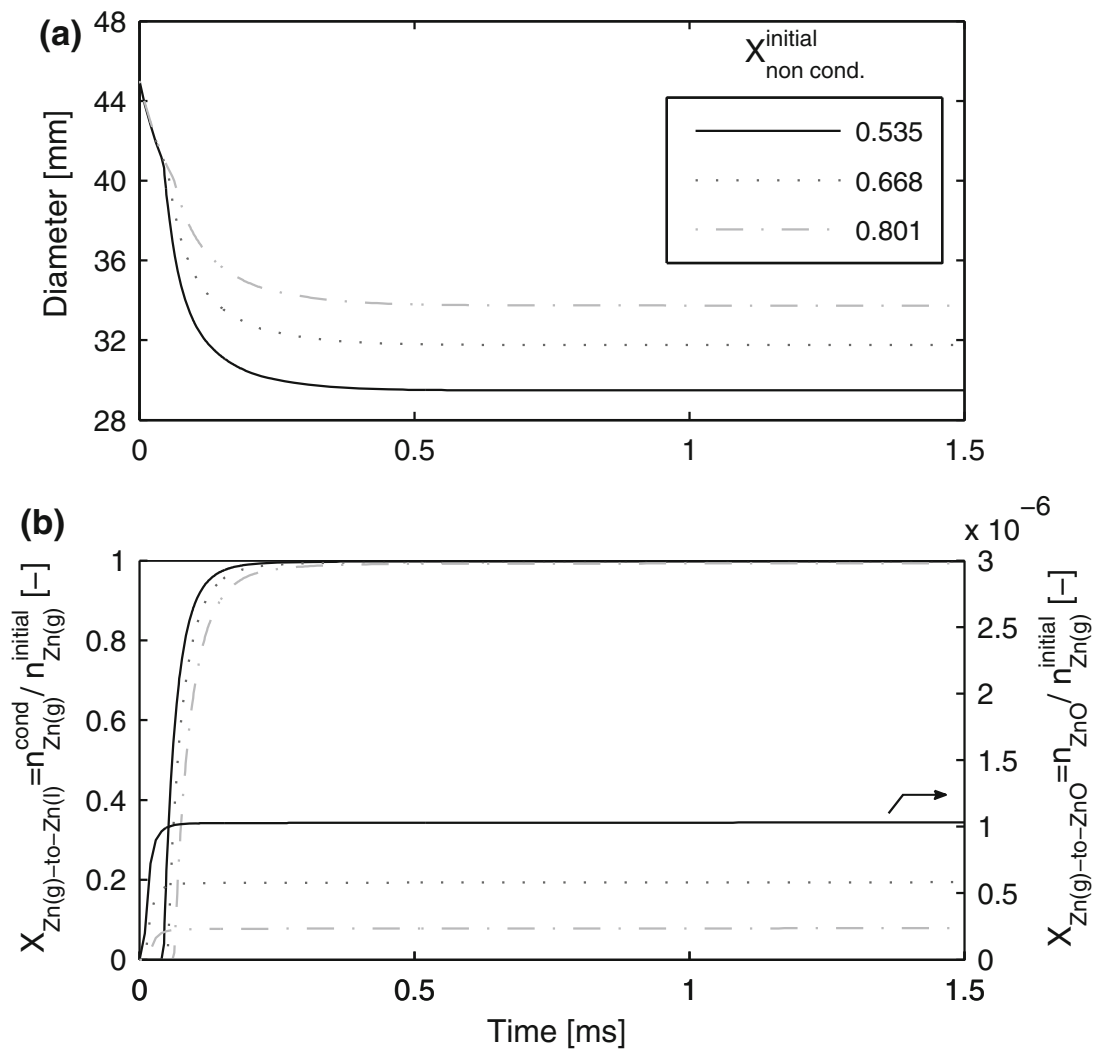

Fig. 9. Effect of the molar fraction of noncondensable gases on the shrinking rate of the bubble and the time variation of the $\mathrm{Zn}(\mathrm{g})$-to- $\mathrm{Zn}(\mathrm{l})$ and $\mathrm{Zn}(\mathrm{g})$-to-ZnO chemical conversions for a bubble with an initial diameter of $45 \mathrm{~mm}$ rising at $0.11 \mathrm{~m} \mathrm{~s}^{-1}$ in a $\mathrm{Zn}(\mathrm{l})$ bath maintained at $500^{\circ} \mathrm{C}$.

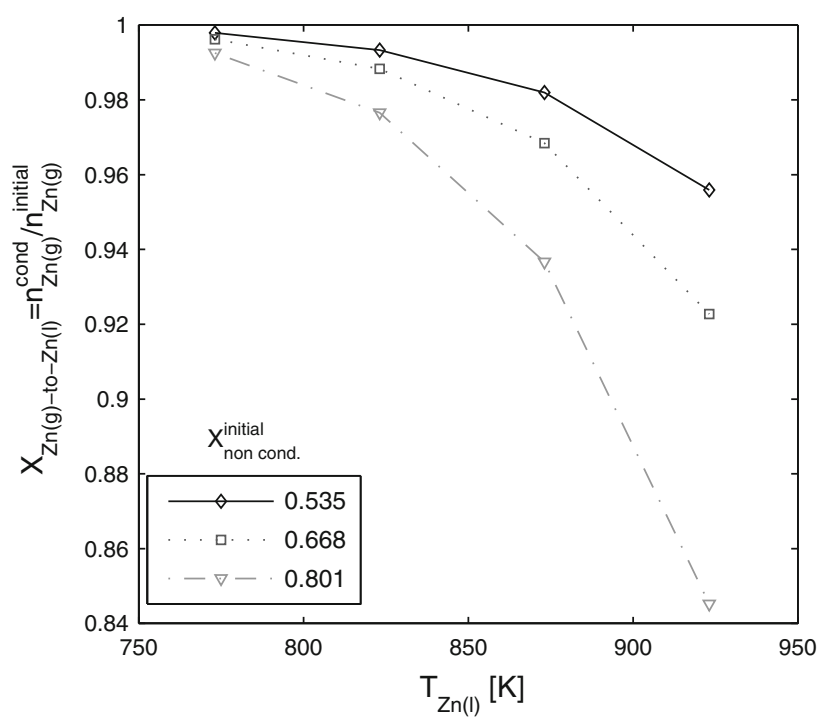

Fig. 10. Effect of the $Z n(I)$ bath temperature and the fraction of noncondensable gases on the conversion of $\mathrm{Zn}(\mathrm{g})$ to $\mathrm{Zn}(\mathrm{l})$.

noncondensable gases in the gas-vapor mixture from $53.5 \%$ to $80.1 \%$ induces a strong nonlinear decrease in the $\mathrm{Zn}(\mathrm{g})$-to- $\mathrm{Zn}(\mathrm{l})$ conversion from 0.956 to 0.845 for condensation in a liquid bath maintained at $650^{\circ} \mathrm{C}$, which is attributed to the effect of their presence on the $\mathrm{Zn}(\mathrm{g})$ partial pressure and the apparent saturation temperature.

\section{Discussion}

Numerical heat- and mass-transfer modeling demonstrates that zinc vapor reoxidation reactions proceed considerably slower than condensation, thus preventing a considerable decrease of the $\mathrm{Zn}(\mathrm{g})$ partial pressure in the undersaturated vapor region due to oxidation by $\mathrm{CO}_{2}$ and $\mathrm{CO}$. The results suggest the technical feasibility of the molten zinc bath condenser concept for zinc gas condensation from high concentration $\mathrm{Zn}(\mathrm{g})$-CO streams such as from a reactor for the solar carbothermal reduction of $\mathrm{ZnO}$. The higher condensation rates obtained with decreasing initial bubble diameter and increasing gas-liquid relative velocity confirm the use of baffles in the $\mathrm{Zn}(\mathrm{l})$ bath to prevent coalescence of individual bubbles, enhance bubble breakup, and improve heat transfer such as that used in the $\mathrm{W}-\mathrm{N}$ condenser. Furthermore, the negligible effect of fraction of noncondensable gases on the condensation efficiency predicted for a highly subcooled liquid bath at $500^{\circ} \mathrm{C}$ is supported by observations on the operation of the pilot-scale W-N condenser mounted at the outlet of the electrothermic zinc furnace at the Josephtown Zinc Smelter. Rapid and almost complete condensation of zinc vapor was reported for 
operation at liquid bath temperatures in the range of $500-525^{\circ} \mathrm{C}$, irrespective of the amount of accompanying noncondensable gases. ${ }^{20}$

\section{CONCLUSION}

A zinc condenser concept involving bubbling of gasvapor products of the solar carbothermal reduction of $\mathrm{ZnO}$ through a subcooled $\mathrm{Zn}(\mathrm{l})$ bath has been proposed to rapidly condense $\mathrm{Zn}(\mathrm{g})$ to $\mathrm{Zn}(\mathrm{l})$ and suppress reoxidation of $\mathrm{Zn}(\mathrm{g})$ by $\mathrm{CO}_{2}$ and $\mathrm{CO}$. A simplified mass- and heat-transfer model was developed to investigate the competing condensation rates and kinetics of oxidation of zinc vapor at solar reactor conditions. A $X_{\mathrm{Zn}(\mathrm{g}) \text {-to-Zn(l) }}$ conversion of 0.992 was predicted for a $45-\mathrm{mm}$-diameter bubble containing $80.1 \%$ noncondensable gases in a liquid bath maintained at $500^{\circ} \mathrm{C}$, whereas successful suppression of the reversion reactions was demonstrated $\left(X_{\mathrm{Zn}(\mathrm{g}) \text {-to-ZnO }}\right.$ $\left.=2.4 \times 10^{-7}\right)$. A notable decrease in the $X_{\mathrm{Zn}(\mathrm{g}) \text {-to-Zn(l) }}$ conversion with increasing temperature due to equilibrium vapor losses supports the operation of a vacuum condenser at low temperatures by efficiently dissipating the large amounts of heat released during the rapid condensation process. The condensation rates were significantly enhanced by a decrease of the initial bubble diameter and increase of the relative velocity between the bubbles and liquid bath. A pronounced decrease of the $\mathrm{Zn}(\mathrm{l})$ yield with increasing fractions of noncondensable gases in the mixture suggests operation with a minimal amount of inert gases to maintain a predicted $X_{\mathrm{Zn}(\mathrm{g}) \text {-to-Zn(1) }}$ above 0.95 in a wide liquid bath temperature range and to minimize the heat liberated in the process.

\section{ACKNOWLEDGEMENTS}

We gratefully acknowledge the financial support by the Swiss Federal Office of Energy (contract SI/ 500660-01) and by European Research Council under the European Union's ERC Advanced Grant (SUNFUELS - No. 320541).

\section{REFERENCES}

1. C.H. Mathewson, Zinc: The Science and Technology of the Metal, Its Alloys and Compounds (London: Reinhold Publication Corporation, 1959).

2. C.H. Cotterill and J.M. Cigan, eds., AIME World Symposium on Mining \& Metallurgy of Lead \& Zinc: Extractive Metallurgy of Lead and Zinc (Englewood: American Institute of Mining, Metallurgical, and Petroleum Engineers, 1970).

3. R.J. Sinclair, The Extractive Metallurgy of Zinc (Victoria: Australasian Institute of Mining and Metallurgy, 2005).

4. S.W.K. Morgan, Bull. Inst. Min. Met. 67, 553 (1957).

5. A. Steinfeld, Energy 22, 311 (1997).

6. T. Osinga, U. Frommherz, A. Steinfeld, and C. Wieckert, J. Sol. Energy Eng. 126, 633 (2004).

7. S. Kräupl, U. Frommherz, and C. Wieckert, J. Sol. Energy Eng. 128, 8 (2006).

8. C. Wieckert, U. Frommherz, S. Kräupl, E. Guillot, G. Olalde, M. Epstein, S. Santén, T. Osinga, and A. Steinfeld, J. Sol. Energy Eng. 129, 190 (2007).

9. M. Epstein, G. Olalde, S. Santén, A. Steinfeld, and C. Wieckert, J. Sol. Energy Eng. 130, 014505 (2008).
10. N. Tzouganatos, R. Matter, C. Wieckert, J. Antrekowitsch, M. Gamroth, and A. Steinfeld, JOM 65, 1733 (2013).

11. S. Kräupl and A. Steinfeld, J. Sol. Energy Eng. 123, 237 (2001).

12. C. Wieckert, M. Epstein, G. Olalde, S. Santén, and A. Steinfeld, Encyclopedia of Electrochemical Power Sources (New York: Elsevier, 2009), pp. 469-486.

13. A. Steinfeld, Sol. Energy 78, 603 (2005).

14. K. Wegner, H.C. Ly, R.J. Weiss, S.E. Pratsinis, and A. Steinfeld, Int. J. Hydrog. Energy 31, 55 (2006).

15. A. Stamatiou, P.G. Loutzenhiser, and A. Steinfeld, AIChE J. 58,625 (2012).

16. D. Weibel, Z.R. Jovanovic, E. Gálvez, and A. Steinfeld, Chem. Mater. 26, 6486 (2014).

17. K.F. Blurton and A.F. Sammells, J. Power Sources 4, 263 (1979).

18. C.B. Solnordal, G.W. Jensen, and F.R.A. Jorgensen (Paper presented at Minprex 2000: International Congress on Mineral Processing and Extractive Metallurgy, 11-13 September 2000, Melbourne, VIC, The Australasian Institute of Mining and Metallurgy (AusIMM) Publication Series), pp. 485-491.

19. G.F. Weaton and H.K. Najarian, U.S. patent US2070101 A (1937).

20. H.K. Najarian, Trans. Am. Inst. Min. Metall. Eng. pp. 161 (1944).

21. H.K. Najarian, Trans. Am. Inst. Min. Metall. Eng. 212, 493 (1958).

22. M. Dell'Amico and J.B. See, Pyrometallurgy 87, 305 (1987).

23. M. Dell'Amico (Master's thesis, The University of Newcastle, 1989).

24. J.V. Scott and D.J. Fray, Advances in Extractive Metallurgy, ed. M.J. Jones (London: Institution of Mining and Metallurgy, 1972), pp. 95-105.

25. A. Cox and D.J. Fray (Paper presented at the Yazawa International Symposium on Metallurgy and Materials Processing: Principles and Technology, 2003), pp. 95-105.

26. J.A. Clarke and D.J. Fray, J. Mater. Sci. 13, 1921 (1978).

27. J.A. Clarke, Chem. Ind. 6, 1 (1979).

28. R.L. Leonard (Master's thesis, Colorado School of Mines, 1985).

29. K.L. Stansbury (Master's Thesis, Colorado School of Mines, 1987).

30. L.A. Lewis and A.M. Cameron, Metall. Mater. Trans. B 26, 911 (1995).

31. L.A. Lewis and A.M. Cameron, Metall. Mater. Trans. B 26, 919 (1995).

32. J.M. Osborne, W.J. Rankin, D.J. McCarthy, and D.R. Swinbourne, Metall. Mater. Trans. B 32, 37 (2001).

33. E.H. Bunce and E.C. Handwerk, Trans. AIME 121, 427 (1936).

34. T. Pedersen, J.A. Aune, and R.A. Cundall, Lead-Zinc 90 (Warrendale: The Minerals, Metals \& Materials Society, 1990), pp. 857-879.

35. C.D. Chapman, P.M. Cowx, J.K. Pargeter, and D.N. Pocklington, Recycl. Met. Mater. (London: Institution of Mining and Metallurgy, 1990), pp. 47-55.

36. G.F. Weaton, H.K. Najarian, and C.C. Long, Trans. TMS AIME 159, 141 (1944).

37. C.C. Long, J. Met. 17, 351 (1965).

38. L. Gourtsoyannis (Master's thesis, McGill University, 1972).

39. A.F. Schoukens, M.A. Abdel-Latif, M.J. Freeman, and N.A. Barcza (Paper presented at the 1996 Electr. Furn. Conference Proceedings, 1996), pp. 341-351.

40. A.F.S. Schoukens, G.M. Denton, and R.T. Jones (Paper presented at the International Symposium on Recycling of Metals and Engineered Materials, Point Clear, AL, 1995), pp. 857-868.

41. P. Neve, U.S. patent US2238819 A (1941).

42. S. Robson and L.J. Derham, U.S. patent US2464262 A (1949).

43. S. Robson and L.J. Derham, U.S. patent US2671725 A (1954).

44. L.J. Derham, U.S. patent US2886309 A (1959). 
45. M.I. Hoschke, U.S. patent US5215572 A (1993).

46. S. Robson, U.S. patent US2473304 A (1949).

47. O. Kubaschewski and C.B. Alcock, Metallurgical Thermochemistry (New York: Pergamon Press, 1979).

48. L. Rayleigh, Philos. Mag. Ser. 6, 94 (1917).

49. M.S. Plesset and A. Prosperetti, Ann. Rev. Fluid Mech. 9, 145 (1977).

50. A.D. Okhotsimskii, Int. J. Heat Mass Transf. 31, 1569 (1988).

51. S.G. Bankoff and R.D. Mikesell, Chem. Eng. Prog. 55, 95 (1959).

52. L.W. Florschuetz and B.T. Chao, J. Heat Transf. 87, 209 (1965).

53. D.D. Wittke and B.T. Chao, J. Heat Transf. 89, 17 (1967).

54. Y.M. Chen and F. Mayinger, Int. J. Multiph. Flow 18, 877 (1992).

55. O. Zeitoun, M. Shoukri, and V. Chatoorgoon, J. Heat Transf. 117, 402 (1995)

56. G.R. Warrier, N. Basu, and V.K. Dhir, Int. J. Heat Mass Transf. 45, 3947 (2002).

57. H. Kalman, Int. J. Heat Mass Transf. 46, 3451 (2003).

58. S.-J. Kim and G.-C. Park, Int. J. Heat Mass Transf. 54, 2962 (2011).

59. H. Kalman, Int. J. Heat Mass Transf. 49, 2391 (2006).

60. G. Rabello dos Anjos and J. Buongiorno, Bubble Condensation Heat Transfer in Subcooled Flow Boiling at PWR Conditions: A Critical Evaluation of Current Correlations (Cambridge: Massachusetts Institute of Technology, 2013).
61. H.R. Jacobs and B.H. Major, J. Heat Transf. 104, 487 (1982).

62. A. Ullmann and R. Letan, J. Heat Transf. 111, 1060 (1989).

63. F.H. Garner and D. Hammerton, Chem. Eng. Sci. 3, 1 (1954).

64. T. Poinsot and D. Veynante, Theoretical and Numerical Combustion, 2nd ed. (Philadelphia: R.T. Edwards Inc., 2005).

65. S. Skogestad, Chemical and Energy Process Engineering (Boca Raton: CRC Press, 2009).

66. G.A. Hughmark, AIChE J. 13, 1219 (1967).

67. R.W. Schrage, A Theoretical Study of Interphase Mass Transfer (New York: Columbia University Press, 1953).

68. R. Marek (Ph.D. thesis, Technical University of Munich, 1996).

69. R. Marek and J. Straub, Int. J. Heat Mass Transf. 44, 619 (2001)

70. R.A. Rapp, J.P. Hirth, and G.M. Pound, J. Chem. Phys. 34 , 184 (1961).

71. G. Söderlind and L. Wang, J. Comput. Appl. Math. 185, 225 (2006).

72. P. Knupp and K. Salari, Verification of Computer Codes in Computational Science and Engineering, 1st ed. (Boca Raton: Chapman and Hall/CRC Press, 2002).

73. W.L. Haberman and R.K. Morton, Trans. Am. Soc. Civ. Eng. 121, 227 (1956).

74. F.C. Gunther, Trans ASME 73, 115 (1951). 